\title{
Epidemiology of hip fractures in Bulgaria: development of a country-specific FRAX model
}

\author{
E. Kirilova ${ }^{1} \cdot$ H. Johansson ${ }^{2} \cdot$ N. Kirilov ${ }^{1} \cdot$ S. Vladeva ${ }^{3} \cdot$ T. Petranova ${ }^{1} \cdot$ Z. Kolarov ${ }^{1} \cdot$ E. Liu ${ }^{2} \cdot$ M. Lorentzon ${ }^{2,4} \cdot$ \\ L. Vandenput ${ }^{2,5} \cdot$ N. C. Harvey ${ }^{6}$ - E. McCloskey ${ }^{7} \cdot$ John A. Kanis ${ }^{2,7}$
}

Received: 11 November 2019 / Accepted: 29 December 2019 / Published online: 27 February 2020

(C) The Author(s) 2020

\begin{abstract}
Summary

A retrospective population-based survey was undertaken in a region of Bulgaria to determine the incidence of hip fracture. The estimated number of hip fractures nationwide for 2015 was 9322 and is predicted to increase to 11,398 in 2050. The hip fracture rates were used to create a FRAX model.

\section{Objective}

To describe the epidemiology of hip fractures in Bulgaria, which was then used to develop the country-specific fracture prediction FRAX® tool.

\section{Methods}

We carried out a retrospective population-based survey in Stara Zagora, Bulgaria, representing approximately $4.6 \%$ of the country's population. We identified hip fractures occurring in 2015, 2016 and 2017 from hospital registers and primary care sources held by the regional health insurance agency. Age- and sex-specific incidence of hip fracture and national mortality rates were incorporated into a FRAX model for Bulgaria. Fracture probabilities were compared with those from neighbouring countries having FRAX models.
\end{abstract}

\section{Results}

The incidence of hip fracture applied nationally suggested that the estimated number of hip fractures nationwide in persons over the age of 50 years for 2015 was 9322 and is predicted to increase to 11,398 in 2050. FRAX-based probabilities were higher in Bulgaria than those in Serbia or Romania, lower than those in Turkey and similar to those in Greece.

\section{Conclusion}

The FRAX model should enhance accuracy of determining fracture probability among the Bulgarian population and help guide decisions about treatment.

Keywords Bulgaria $\cdot$ FRAX $\cdot$ Fracture probability $\cdot$ Epidemiology $\cdot$ Hip fracture

\section{Introduction}

Osteoporosis and osteoporotic fractures are becoming more common with advancing age. In Europe, the annual cost of

John A. Kanis

w.j.pontefract@sheffield.ac.uk

Medical University of Sofia, Sofia, Bulgaria

2 Mary MacKillop Institute for Health Research, Australian Catholic University, Melbourne, Australia

3 Medical Faculty, Trakia University, Stara Zagora, Bulgaria fractures associated with osteoporosis exceeded $€ 37$ billion in 2010 [1], and disability due to osteoporosis was greater than that caused by any single cancer, with the exception of lung cancer and was comparable or greater than that lost to a variety

4 Geriatric Medicine, Institute of Medicine, University of Gothenburg, Gothenburg, Sweden

5 Centre for Bone and Arthritis Research, Institute of Medicine, University of Gothenburg, Gothenburg, Sweden

6 MRC Lifecourse Epidemiology Unit, University of Southampton, Southampton, UK

7 Centre for Metabolic Bone Diseases, University of Sheffield, Sheffield, UK 
of chronic non-communicable diseases, such as rheumatoid arthritis, asthma and high blood pressure-related heart disease [2]. Fortunately, a wide variety of treatments is available that favourably affect bone mass and thereby decrease the risk of fractures associated with osteoporosis [3]. The use of such interventions by healthcare practitioners is assisted by instruments that assess patients' fracture risk to optimise clinical decisions about prevention and treatment. The most widely used web-based tool FRAX® (https:/www.sheffield.ac.uk/ FRAX/) meets these requirements and computes the 10-year probability of fragility fractures based on several common clinical risk factors and optionally, a DXA scan result [4, 5]. FRAX models are available for 66 countries covering more than $80 \%$ of the world population at risk [6] and have been incorporated into more than 100 guidelines worldwide [7].

The availability of FRAX has stimulated studies for the generation of new FRAX models. Specific examples include Brazil, Mexico, Turkey [8-10] and several countries in Eastern Europe [11-14]. The present report describes the epidemiology of fractures at the hip in Bulgaria and the generation of a country-specific FRAX model.

\section{Methods}

Bulgaria is a country in Southeastern Europe with a total area of $110,994 \mathrm{~km}^{2}$. It borders the Black Sea to the east, Greece and Turkey to the south, Serbia and Macedonia to the west and Romania to the north [15]. According to the national statistical institute, the Bulgarian population comprises four ethnic groups as follows: Bulgarian (84.8\%), Turkish (8.8\%), Roma (4.9\%) and others (1.5\%) [16].

Stara Zagora, in Southern Bulgaria, is the sixth-largest city in Bulgaria. Based on regional health inspection's data, the region's population aged 40 years or above in 2017 amounted to 183,294 people $(84,557$ men and 98,737 women) and represented $4.6 \%$ of the whole Bulgarian population aged 40 years and above $(183,294 / 3,982,770)$. The ethnic admixture of Stara Zagora is similar to the country as a whole.

We analysed the cases of hip fractures (ICD codes: S72.0, S72.1 and S72.2) in the Stara Zagora region, Bulgaria, for the years 2015, 2016 and 2017. Data were provided by the Regional Health Insurance Fund (RHIF) Stara Zagora using an electronic database of hospitals, general practitioners and specialists in this region. The insurance company covers $81.2 \%$ of the total population but coverage varies according to age and sex. The relevant data on coverage was available and the age- and sex-specific insured population comprised the denominator for the calculation of incidence. To minimise double counting, further admissions for the same hip fracture site within 3 months were excluded. Permanent residence in the region was not a criterion for inclusion, so a small number of patients living temporarily in the catchment area were also included in the database.

Incidence of hip fractures was calculated from the age of 40 years in 5-year age intervals in men and in women. The age of 40 was chosen since FRAX permits the calculation of fracture probability from this age.

The age- and sex-specific incidence for 2015-2017 was applied to the Bulgarian population for 2015 to estimate the number of hip fractures nationwide. Additionally, future projections were estimated up to 2050, assuming that the age- and sex-specific incidence remained stable. Population demography was taken from the United Nations using the medium variant for fertility [17].

The data on hip fracture were used to construct a FRAX model for Bulgaria. For other major osteoporotic fractures (clinical spine, forearm and humeral fractures), it was assumed that the age- and sex-specific ratios of these fractures to hip fracture risk in Bulgaria were comparable with those found in Sweden [4]. This assumption has been used for many of the FRAX models with incomplete epidemiological information on non-hip fractures. Available information suggests that the age- and sex-stratified pattern of fracture is very similar in the Western world and Australia [14, 18-20].

The development and validation of FRAX have been extensively described $[4,5]$. The risk factors used were based on a systematic set of meta-analyses of population-based cohorts worldwide and validated in independent cohorts with over 1 million patient-years of follow-up. The construct of the FRAX model for Bulgaria retained the beta coefficients of the risk factors in the original FRAX model with the incidence rates of hip fracture and mortality rates for Bulgaria. National mortality rates used data from the United Nations in 2014 [21]. Tenyear fracture probabilities were compared with those of neighbouring countries with FRAX models (Greece, Serbia, Turkey and Romania).

In order to compare Bulgarian hip fracture probabilities with those of other regions of the world, the remaining lifetime probability of hip fracture from the age of 50 years was calculated for men and women as described by Kanis et al. [22]. In the present analysis, values for Bulgaria were compared with those of China (with and without inclusion of Hong Kong), Canada, Denmark, Finland, France, Greece, Hungary, Portugal, Spain, Sweden, UK and the USA [22], with more recent additions from Mexico [23], Romania [24], Poland [25], Moldova [14], Russia [12], Turkey [10], Ukraine [26] and Serbia [27].

\section{Results}

A total of 367 hip fractures were identified in men and 1017 in women (female/male ratio 2.8). Below the age of 65 years, hip fractures were more prevalent in men than in women (female/ 
male ratio 0.7 ), but thereafter were more frequent in women (female/male ratio 3.2). The incidence of hip fracture increased with age in men and women, though more markedly in women (Table 1).

\section{Hip fracture projections}

Assuming that the fracture rates in Stara Zagora were representative for the whole country and based on the UN estimates of the Bulgarian population for 2015, we estimated that the annual number of hip fractures in men and women aged 50 years and older in Bulgaria in 2015 was 9322 , comprising 2521 in men and 6801 fractures in women. The number of hip fractures is expected to increase progressively by calendar year with an increase of $22 \%$ by 2050 (Table 2 ). The increase in hip fracture numbers was higher in women ( $24 \%$ in women

Table 1 Population of the catchment area, number of hip fractures and annual incidence of hip fractures (rate/100,000) in men and women in Stara Zagora, Bulgaria, by age for years 2015, 2016 and 2017 combined

\begin{tabular}{llll}
\hline Age (years) & Population $^{\mathrm{a}}$ Fractures $^{\mathrm{b}}$ & $\begin{array}{l}\text { Incidence/ } \\
100,000\end{array}$ & 95\% CI
\end{tabular}

\begin{tabular}{|c|c|c|c|c|}
\hline \multicolumn{5}{|l|}{ Men } \\
\hline $40-44$ & 28,257 & 9 & 32 & $15-60$ \\
\hline $45-49$ & 27,267 & 14 & 51 & $28-86$ \\
\hline $50-54$ & 26,372 & 18 & 68 & $40-108$ \\
\hline $55-59$ & 27,646 & 26 & 94 & 61-138 \\
\hline $60-64$ & 27,889 & 35 & 125 & $87-175$ \\
\hline $65-69$ & 27,903 & 37 & 133 & 93-183 \\
\hline $70-74$ & 20,886 & 44 & 211 & $153-283$ \\
\hline $75-79$ & 15,632 & 54 & 345 & $259-451$ \\
\hline $80-84$ & 11,131 & 54 & 485 & $364-633$ \\
\hline $85-89$ & 4832 & 53 & 1097 & $822-1435$ \\
\hline $90+$ & 1292 & 23 & 1780 & $1128-2672$ \\
\hline $40+$ & 219,106 & 367 & 167 & $151-186$ \\
\hline \multicolumn{5}{|l|}{ Women } \\
\hline $40-44$ & 28,069 & 3 & 11 & $2-31$ \\
\hline $45-49$ & 26,998 & 7 & 26 & $10-53$ \\
\hline $50-54$ & 27,768 & 12 & 43 & $22-76$ \\
\hline $55-59$ & 30,383 & 24 & 79 & 51-118 \\
\hline $0-64$ & 34,907 & 36 & 103 & $72-143$ \\
\hline $65-69$ & 38,011 & 60 & 158 & $120-203$ \\
\hline $70-74$ & 30,842 & 95 & 308 & $249-377$ \\
\hline $75-79$ & 24,652 & 189 & 767 & $661-884$ \\
\hline $80-84$ & 19,278 & 261 & 1354 & $1195-1529$ \\
\hline $85-89$ & 9247 & 247 & 2671 & 2348-3026 \\
\hline $90+$ & 2862 & 83 & 2900 & $2310-3595$ \\
\hline $40+$ & 273,018 & 1017 & 373 & $350-396$ \\
\hline
\end{tabular}

${ }^{\text {a }}$ Population corrected for insurance cover

${ }^{\mathrm{b}}$ Fractures per year over 3 years
Table 2 Estimated total number of hip fractures (ICD-10 codes S72.0, S72.1, S72.2) in men and in women aged 50 years and older in 2015 projected up to 2050 in Bulgaria

\begin{tabular}{lrrrrr}
\hline & 2015 & 2020 & 2030 & 2040 & \multicolumn{1}{c}{2050} \\
\hline Men & 2521 & 2567 & 2739 & 2903 & 2973 \\
Women & 6801 & 7136 & 7923 & 8397 & 8425 \\
Total & 9322 & 9703 & 10,662 & 11,300 & 11,398 \\
Increase (\%) & - & 4 & 14 & 21 & 22 \\
\hline
\end{tabular}

and $18 \%$ in men) due to the high age dependency of hip fracture incidence.

\section{Fracture probability}

The 10-year probability of major osteoporotic fracture and hip fracture in Bulgaria and neighbouring countries is shown in Table 3 in women with a prior fracture by age. Ten-year probabilities were consistently higher than those in the neighbouring countries of Serbia and Romania, lower than those in Turkey and similar to those in Greece.

For the remaining lifetime probability of a hip fracture in Bulgarian women from the age of 50 years was $11.2 \%$ which lay midway between Romania and Serbia (7.1 and 7.7\%,

Table 3 Ten-year probability of a major osteoporotic fracture (MOF) and hip fracture in women with a prior fracture by age from Bulgaria, Greece, Turkey, Serbia and Romania. Body mass index set to $25 \mathrm{~kg} / \mathrm{m}^{2}$

\begin{tabular}{cccccc}
\hline & Bulgaria & Greece & Turkey & Serbia & Romania \\
\hline MOF & & & & & \\
50 & 7.7 & 5.2 & 8.2 & 4.5 & 5.2 \\
55 & 8.5 & 7.0 & 8.2 & 6.1 & 6.5 \\
60 & 9.5 & 9.8 & 8.6 & 8.4 & 7.9 \\
65 & 11 & 13 & 10 & 11 & 9.5 \\
70 & 15 & 17 & 13 & 13 & 11 \\
75 & 19 & 22 & 18 & 14 & 13 \\
80 & 22 & 25 & 24 & 15 & 13 \\
85 & 23 & 25 & 33 & 15 & 13 \\
90 & 20 & 20 & 37 & 14 & 11 \\
Hip & & & & & \\
50 & 1.2 & 0.8 & 1.3 & 0.7 & 0.8 \\
55 & 1.6 & 1.3 & 1.5 & 1.2 & 1.2 \\
60 & 2.1 & 2.2 & 1.8 & 1.9 & 1.8 \\
65 & 2.9 & 3.4 & 2.3 & 2.9 & 2.6 \\
70 & 4.5 & 5.4 & 4.1 & 4.2 & 3.5 \\
75 & 7.0 & 8.3 & 7.5 & 5.3 & 4.6 \\
80 & 9.6 & 11 & 11 & 5.8 & 5.4 \\
85 & 11 & 12 & 16 & 6.7 & 5.8 \\
90 & 9.4 & 9.3 & 17 & 7.3 & 4.5 \\
\hline & & & & &
\end{tabular}


respectively) and those of Greece and Turkey (15.4 and $15.9 \%$, respectively) (Table 4 ).

\section{Discussion}

The present study characterised the regional incidence of hip fracture in a well-defined catchment area. The hip fracture incidence increased with age in both sexes, but below the age of 65 years was higher in men than in women. Thereafter, incidence was higher in women. Similar results have been reported in many studies including other countries in Eastern Europe, namely Russia [12], Armenia [11], Moldova [14] and Belarus, [13]. From these results, Bulgaria belongs to the moderate risk countries for osteoporotic hip fracture for men and women [28].

Based on the regional incidence, the number of hip fractures in 2015 was estimated at 9322 for the whole country and is expected to increase by $22 \%$ to 11,398 in 2050 . These estimates are relatively robust, in that all individuals who will

Table 4 Lifetime probability of hip fracture in the Bulgarian population from the age of 50 years compared with selected countries

\begin{tabular}{|c|c|c|}
\hline \multirow[t]{2}{*}{ Country } & \multicolumn{2}{|c|}{ Lifetime risk at 50 years $(\%)^{\mathrm{a}}$} \\
\hline & Women & Men \\
\hline Sweden & 25.6 & 11.0 \\
\hline Denmark & 23.0 & 11.3 \\
\hline France & 19.3 & 5.9 \\
\hline China (Hong Kong) & 17.7 & 7.6 \\
\hline USA (Caucasian) & 16.1 & 7.5 \\
\hline Turkey & 15.9 & 3.6 \\
\hline Canada & 15.5 & 5.8 \\
\hline Greece & 15.4 & 6.8 \\
\hline UK & 14.4 & 5.0 \\
\hline Portugal & 13.7 & 4.8 \\
\hline Finland & 12.9 & 6.0 \\
\hline Spain & 12.6 & 4.2 \\
\hline Bulgaria $^{\mathrm{b}}$ & 11.2 & 4.4 \\
\hline Hungary & 10.8 & 4.2 \\
\hline Mexico & 10.6 & 5.0 \\
\hline Poland & 10.1 & 4.2 \\
\hline Moldova & 9.3 & 5.7 \\
\hline Russia & 7.7 & 3.8 \\
\hline Serbia & 7.7 & 3.7 \\
\hline Romania & 7.1 & 3.8 \\
\hline China & 5.9 & 3.3 \\
\hline Ukraine & 5.6 & 2.9 \\
\hline
\end{tabular}

${ }^{a}$ Probabilities derived from fracture as given in FRAX v4.1 and updated death risks

${ }^{\mathrm{b}}$ Present study be aged 60 years or more in 2050 are currently adults. However, these estimates may be conservative since they assume that the age- and sex-specific risk of hip fracture remains unchanged over this period. Decreases in age-specific rates have occurred in those countries with the higher hip fracture risks [29], whereas increases in incidence with time are commonly found in those countries with the lower risks. It is estimated that modest increases in secular trends (e.g. $1 \%$ per year) as seen for example in Mexico [9] together with demographic changes would double the number of hip fractures over 20 years [30]. Such projections are important for healthcare planning.

The incidence of hip fracture and of death was used to create a country-specific FRAX model for Bulgaria. Tenyear probabilities of fracture were consistently higher than those in the neighbouring countries of Serbia and Romania, lower than those in Turkey and similar to those in Greece. These differences in fracture probability cannot be accounted for by differences in mortality but rather reflect differences in the risk of hip fracture. Reasons for the heterogeneity in hip fracture risk are speculative [9]. The factor which best predicts the heterogeneity in hip fracture risk is socioeconomic prosperity that in turn may be related to low levels of physical activity [31]. The fact that there are differences in adjacent countries emphasizes the importance of the use of country-specific FRAX models rather than surrogate models [32].

A minority of countries that have a FRAX model also have robust information on the risk of other major osteoporotic fractures. In the absence of such information, FRAX models are based on the assumption that the age- and sex-specific pattern of these fractures is similar to that observed in Malmo, Sweden [33]. The acquisition of data on the incidence of forearm and humerus fractures in a manner identical to that for hip fracture permitted the adequacy of this assumption to be tested, at least for forearm and humeral fractures. Our findings suggest that the incidence of forearm and humerus fractures can be reasonably predicted from the incidence of hip fracture. Very similar findings have been reported from Canada [20], Iceland [19], USA [34], UK [35], Australia [36] and several additional countries of the Western world and Australia, despite differences in incidence [28]. This commonality of pattern is supported by register studies, which indicate that in those regions where hip fracture rates are high, so too is the risk of forearm fracture and spine fractures (requiring hospital admission) [37, 38].

In most countries, a case finding approach is used for the management of osteoporosis, where certain clinical risk factors (CRFs) for fracture suggest the possible diagnosis of osteoporosis and trigger a more detailed assessment of the need for intervention. Many assessment guidelines recommend that women with a prior fracture are eligible for treatment. By the same token, individuals with a fracture probability that is 
equivalent to or greater than that of women with a prior fracture should also be eligible. Age-specific intervention thresholds have been widely used in Europe and South America [7] If the same strategy were used in Bulgaria, the intervention would be recommended in individuals with a 10-year probability of a major osteoporotic fracture that ranged from 7.7 to $23 \%$, depending on age (see Table 3 ).

There are a number of limitations to this study. The accuracy of the register is not known. With regard to fracture incidence, we examined somewhat less than 5\% of the Bulgarian population. Therefore, the extrapolation of these regional estimations to the entire country is an assumption that we were unable to test. This would require a national survey and its validity tested in prospective study of a population-based cohort. Moreover, a minority of the population was not included in the regional health insurance fund and an imbalance in health status may have skewed our estimates. In addition to large variations in fracture rates around the world, fracture rates may vary within countries. In addition to ethnicspecific differences [39], up to twofold differences in hip fracture incidence have been reported using common methodology with the higher rates in urban communities including Croatia [40], Switzerland [41], Norway [42], Argentina [43] and Turkey [44].

Despite the well-defined catchment population, it is possible that not all hip fractures were captured. Indeed, many patients in Eastern Europe are not hospitalized because facilities for surgical management are limited, so that hospital admission is not always feasible. In Belarus, for example, $29 \%$ cases of hip fracture did not come to hospital attention [13]. High rates of non-admittance have been reported in Armenia (44\%) [11] Pervouralsk in Russia (27\%) [12], Georgia (75\%) and Kyrgyzstan (50\%) [45].

It is relevant, however, that accuracy errors have little impact on the rank order with which the FRAX tool categorises risk in a given population [11, 46], but they do change the absolute number generated and thus have implications where treatment guidelines are based on cost-effectiveness or the economic burden of disease. In order to address these limitations, population representatives of the general population at risk would need to be studied prospectively, preferably over a 10-year time horizon.

In summary, a FRAX model has been created for Bulgaria based on a regional population-based estimate of the incidence of low energy hip fractures. The model should enhance accuracy of determining fracture probability among the Bulgarian population and help to guide decisions about treatment.

\section{Compliance with ethical standards}

Conflict of interest E Kirilova, H Johansson, N Kirilov, S Vladeva, T Petranova, E Liu, L Vanderput and Z Kolarov declare that they have no competing interests. M Lorentzon has received lecture or consulting fees from Amgen, Lilly, UCB Pharma, Radius Health, Renapharma, Meda, GE-Lunar, Consilient Health and Tromp Medical. NC Harvey reports personal fees, consultancy, lecture fees and honoraria from Alliance for Better Bone Health, AMGEN, MSD, Eli Lilly, Servier, Shire, UCB, Kyowa Kirin, Consilient Healthcare, Radius Health and Internis Pharma outside the submitted work. EV McCloskey reports personal fees, consultancy, lecture fees, research support and/or honoraria from Amgen, AstraZeneca, Consilient Healthcare, Fresenius Kabi, GSK, Hologic, Internis, Lilly, Merck, Novartis, Pfizer, Roche, Sanofi-Aventis, Servier, Synexus, UCB, Warner Chilcott outside the submitted work. He also reports research support from Versus Arthritis, I3 Innovus, MRC and IOF outside the submitted work. JA Kanis reports grant support from Amgen, Lilly and Radius Health.

Open Access This article is licensed under a Creative Commons Attribution 4.0 International License, which permits use, sharing, adaptation, distribution and reproduction in any medium or format, as long as you give appropriate credit to the original author(s) and the source, provide a link to the Creative Commons licence, and indicate if changes were made. The images or other third party material in this article are included in the article's Creative Commons licence, unless indicated otherwise in a credit line to the material. If material is not included in the article's Creative Commons licence and your intended use is not permitted by statutory regulation or exceeds the permitted use, you will need to obtain permission directly from the copyright holder. To view a copy of this licence, visit http://creativecommons.org/licenses/by/4.0/.

\section{References}

1. Hernlund E, Svedbom A, Ivergård M, Compston J, Cooper C, Stenmark J, McCloskey EV, Jönsson B, Kanis JA (2013) Osteoporosis in the European Union: medical management, epidemiology and economic burden. A report prepared in collaboration with the International Osteoporosis Foundation (IOF) and the European Federation of Pharmaceutical Industry Associations (EFPIA). Arch Osteoporos 8:136

2. Johnell O, Kanis JA (2006) An estimate of the worldwide prevalence and disability associated with osteoporotic fractures. Osteoporos Int 17:1726-1733

3. Kanis JA, Cooper C, Rizzoli R, Reginster J-Y, Scientific Advisory Board of the European Society for Clinical and Economic Aspects of Osteoporosis (ESCEO) and the Committees of Scientific Advisors and National Societies of the International Osteoporosis Foundation (IOF) (2019) European guidance for the diagnosis and management of osteoporosis in postmenopausal women. Osteoporos Int 30:3-44

4. Kanis JA On behalf of the World Health Organization Scientific Group (2008a) Assessment of osteoporosis at the primary healthcare level. Technical Report. WHO Collaborating Centre, University of Sheffield, UK. Available at http://www.shef.ac.uk/ FRAX/pdfs/WHO_Technical_Report.pdf. Accessed 26 Feb 2019

5. Kanis JA, Johnell O, Oden A, Johansson H, McCloskey E (2008b) FRAX $^{\mathrm{TM}}$ and the assessment of fracture probability in men and women from the UK. Osteoporos Int 19:385-397

6. Odén A, McCloskey EV, Kanis JA, Harvey N, Johansson H (2015) Burden of high fracture probability. Osteoporos Int 26:2243-2248

7. Kanis JA, Harvey NC, Cyrus Cooper C, Johansson H, Odén A, McCloskey EV, The Advisory Board of the National Osteoporosis Guideline Group (2016) A systematic review of intervention thresholds based on FRAX. A report prepared for the National Osteoporosis Guideline Group and the International Osteoporosis Foundation. Arch Osteoporos 11(1):25 
8. Zerbini CAF, Szejnfeld VL, Abergaria BH, McCloskey EV, Johansson H, Kanis JA (2015) Incidence of hip fracture in Brazil and the development of a FRAX model. Arch Osteoporos 10(1):224

9. Johansson H, Clark P, Carlos F, Oden A, McCloskey EV, Kanis JA (2011) Increasing age- and sex-specific rates of hip fracture in Mexico: a survey of the Mexican institute of social security. Osteoporos Int 22:2359-2364

10. Tuzun S, Eskiyurt N, Akarırmak U, Sarıdoğan M, Johansson H, Kanis JA, Turkish Osteoporosis Society (2012) The impact of FRAX-based intervention thresholds in Turkey: the FRAXTURK study. Arch Osteoporos 7:229-235

11. Lesnyak O, Sahakyan S, Zakroyeva A, Bilezikian JP, Hutchings N, Galstyan R, Lebedev A, Johansson H, Harvey NC, McCloskey E, Kanis JA (2017) Epidemiology of fractures in Armenia: development of a country-specific FRAX model and comparison to its surrogate. Arch Osteoporos 12(1):98-99. https://doi.org/10.1007/ s11657-017-0392-6

12. Lesnyak O, Ershova O, Belova K, Gladkova E, Sinitsina O, Ganert O, Romanova M, Khodirev V, Johansson H, McCloskey E, Kanis JA (2012) Epidemiology of fracture in the Russian Federation and the development of a FRAX model. Arch Osteoporos 7:67-73

13. Ramanau H, Chernyanin I, Rudenka E, Lesnyak O, Zakroyeva A, Bilezikian JP, Johansson H, Harvey NC, McCloskey EV, Kanis JA (2018) Epidemiology of hip fracture in Belarus: development of a country-specific FRAX model and its comparison to neighboring country models. Arch Osteoporos 13:42

14. Zakroyeva A, Lesnyak O, Cazac V, Groppa L, Russu E, Chislari L, Rotaru L, Johansson H, Harvey NC, McCloskey E, Kanis JA (2019) Epidemiology of osteoporotic fracture in Moldova and development of a country specific FRAX model. Submitted to Archives June 2019 Minor revisions and resubmitted (Sept 2019)

15. Bulgaria doing business for everyone guide-Practical Information and Contacts, 2013 Edition Updated Reprint International Business Publication, USA ISBN 1-4387-7175-4 89

16. National statistical institute republic Bulgaria census2011/ PDOCS2/Census2011. http://www.nsi.bg/census2011/PDOCS2/ Census2011final_en.pdf

17. United Nations (2017) DESA/population division. World Population Prospects 2017 https://population.un.org/wpp/ Download/Standard/Population/. Accessed 15 Feb 2019

18. Kanis JA, Oden A, Johnell O, Jonsson B, de Laet C, Dawson A (2001) The burden of osteoporotic fractures: a method for setting intervention thresholds. Osteoporos Int 12:417-427

19. Siggeirsdottir K, Aspelund T, Johansson H, Gudmundsson EF, Mogensen B, Jonsson BY, Gudnason V, McCloskey E, Oden A, Sigurdsson G, Kanis JA (2014) The incidence of a first major osteoporotic fracture in Iceland and implications for FRAX. Osteoporos Int 25:2445-2451

20. Lam A, LeslieWD LLM, Yogendran M, Morin SN, Majumdar SR (2014) Major osteoporotic to hip fracture ratios in Canadian men and women with Swedish comparisons: a population-based analysis. J Bone Miner Res 29:1067-1073

21. United Nations (2010) Population Division of the Department of Economic and Social Affairs of the United Nations Secretariat, World Population Prospects: http://esa.un.org/unpd/wpp/unpp/ panel_indicators.htm Accessed Nov 2011

22. Kanis JA, Johnell O, De Laet C, Jonsson B, Oden A, Ogelsby AK (2002) International variations in hip fracture probabilities: implications for risk assessment. J Bone Miner Res 17:1237-1244

23. Clark P, Lavielle P, Franco-Morina F, Ramirez E, Salmeron J, Kanis JA, Cummings SR (2005) Incidence rates and life-time risk of hip fractures in Mexicans over 50 years of age: a population-based study. Osteoporos Int 16:2025-2030
24. Grigorie D, Sucaliuc A, Johansson H, Kanis JA, McCloskey E (2013) Incidence of hip fracture in Romania and the development of a Romanian FRAX model. Calcif Tiss Int 92:429-436

25. Czerwinski E, Kanis JA, Trybulec B, Johansson H, Borowy P, Osieleniec J (2009) The incidence and risk of hip fracture in Poland. Osteoporos Int 20:1363-1367

26. Povoroznyuk VV, Grygorieva NV, Kanis JA, McCloskey EV, Johansson H, Harvey NC, Korzh MO, Strafun SS, Vaida VM, Klymovytsky FV, Vlasenko RO, Forosenko VS (2017) Epidemiology of hip fracture and the development of FRAX in Ukraine. Arch Osteoporos 12:53

27. Johansson H, Matijevic R, Harhaji V, McCloskey EV, Harvey NC, Lorentzon M, Liu E, Kanis JA (2019) Ten-year fracture probability in Serbia according to age and other FRAX models in the region. Osteoporos Int 30(Suppl 1):P591

28. Kanis JA, Oden A, McCloskey EV, Johansson HD, Wahl A, Cooper C (2012) A systematic review of hip fracture incidence and probability of fracture worldwide. Osteoporos Int 23(9): 2239-2256

29. Cooper C, Cole ZA, Holroyd CR, Earl SC, Harvey NC, Dennison EM, Melton LJ, Cummings SR, Kanis JA, IOF CSA Working Group on Fracture Epidemiology (2011) Secular trends in the incidence of hip and other osteoporotic fractures. Osteoporos Int 22: $1277-1288$

30. Gullberg B, Johnell O, Kanis JA (1997) World-wide projections for hip fracture. Osteoporos Int 7:407-413

31. Johnell O, Borgstrom F, Jonsson B, Kanis J (2007) Latitude, socioeconomic prosperity, mobile phones and hip fracture risk. Osteoporos Int 18:333-337

32. Cauley JA, El-Hajj Fuleihan G, Arabi A, Fujiwara S, Ragi-Eis S, Calderon A, Chionh SB, Chen Z, Curtis JR, Danielson ME, Hanley DA, Kroger H, Kung AW, Lesnyak O, Nieves J, Pluskiewicz W, El Rassi R, Silverman S, Schott AM, Rizzoli R, Luckey M, FRAX® Position Conference Members (2011) Official positions for FRAX clinical regarding international differences from Joint Official Positions Development Conference of the International Society for Clinical Densitometry and International Osteoporosis Foundation on FRAX. J Clin Densitom 14(3):240e262

33. Kanis JA, Hans D, Cooper C, Baim S, Bilezikian JP, Binkley N, Compston J, Dawson-Hughes B, El-Hajj Fuleihan G, Johansson H, Leslie WD, Lewiecki EM, Luckey MM, Oden A, Papapoulos SE, Poiana C, Wahl DA, McCloskey E, Task Force of the FRAX Initiative (2011) Interpretation and use of FRAX in clinical practice. Osteoporos Int 22:395-411

34. Melton LJ, Crowson CS, O'Fallon WM (1999) Fracture incidence in Olmsted County, Minnesota: comparison of urban and with rural rates and changes in urban rates over time. Osteoporos Int 9:29-37

35. Singer BR, McLauchlan CJ, Robinson CM, Christie J (1998) Epidemiology of fracture in 15.000 adults. The influence of age and gender. J Bone Joint Surg 80B:234-238

36. Sanders KM, Seeman E, Ugoni AM, Pasco JA, Martin TJ, Skoric B, Nicholson GC, Kotowicz MA (1999) Age- and gender-specific rate of fractures in Australia: a population-based study. Osteoporos Int 10(2):40-47

37. Johnell O, Gullberg B, Kanis JA (1997) The hospital burden of vertebral fracture in Europe: a study of national register sources. Osteoporos Int 7:138-144

38. Melton LJ (1995) Epidemiology of fractures. In: Riggs BL, Melton LJ (eds) Osteoporosis: etiology, diagnosis and management, 2nd edn. Lippincott-Raven, Philadelphia, pp 225-227

39. Cauley JA, Chalhoub D, Kassem AM, Fuleihan G-H (2014) Geographic and ethnic disparities in osteoporotic fractures. Nat Rev Endocrinol 10:338-351

40. Karacić TP, Kopjar B (2009) Hip fracture incidence in Croatia in patients aged 65 years and more. Lijec Vjesn 131:9-13 
41. Lippuner K, Johansson H, Kanis JA, Rizzoli R (2010) FRAX assessment of osteoporotic fracture probability in Switzerland. Osteoporos Int 21:381-389

42. Emaus N, Olsen LR, Ahmed LA, Balteskard L, Jacobsen BK, Magnus T, Ytterstad B (2011) Hip fractures in a city in northern Norway over 15 years: time trends, seasonal variation and mortality: the Harstad injury prevention study. Osteoporos Int 22: 2603-2610

43. Morosano M, Masoni A, Sánchez A (2005) Incidence of hip fractures in the city of Rosario. Argentina: Osteoporos Int 16:13391344

44. Elffors L, Allander E, Kanis JA, Gullberg B, Johnell O, Dequeker J, Dilzen G, Gennari C, Lopez-Vaz AA, Lyritis G, Mazzuoli GF, Miravet L, Passeri M, Perez Cano R, Rapado A, Ribot C (1994)
The variable incidence of hip fracture in southern Europe. The MEDOS study. Osteoporos Int 4:253-263

45. International Osteoporosis Foundation (2011) The Eastern European \& Central Asian Regional Audit. Epidemiology, costs $\&$ burden of osteoporosis in 2010. Naturaprint, France. Available at www.iofbonehealth.org/sites/default/files/PDFs/Audit\% 20Eastern\%20Europe_Centra1\%20Asia/Eastern_European_ Central_Asian_Audit_2010.pdf. Accessed 11 Dec 2018

46. Kanis JA, Johansson $\bar{H}$, Oden A, Dawson-Hughes B, Melton LJ 3rd, McCloskey EV (2010) The effects of a FRAX® revision for the USA. Osteoporos Int 21:35-40

Publisher's note Springer Nature remains neutral with regard to jurisdictional claims in published maps and institutional affiliations. 